\title{
FOREST MANAGEMENT TO MITIGATE DISASTERS CAUSED BY HEAVY RAIN
}

\author{
KOJI TAMAI \\ Forestry and Forest Products Research Institute, Japan
}

\begin{abstract}
Establishment of forest management methods to balance disaster mitigation function with timber production function has been sought in Japan. Forest maturity is thought to have improved its function to mitigate slope failures and flood disasters contributed by the reinforcing effect of slope stability by root system. It is ideal to avoid cutting down of forests with disaster occurrence risk. However, when cutting down of trees might be unavoidable for production of timber, harvested forest should be selected by disaster-occurrence risk and distance from residential area. Moreover, measures should be taken so that an increase in the disaster occurrence risk is suppressed to the greatest degree possible, such as suppression of the amount to be cut down and quick replanting after cut down.
\end{abstract}

Keywords: reinforcing effect of slope stability by root system, slope failure, reforestation.

\section{INTRODUCTION}

Precipitation amounts are high in Japan. Not uncommonly, hourly precipitation reaches as high as several hundred milli meters because of typhoons and Baiu front. Crustal movement is active in Japan. Therefore mountain slope stability is low. Slope failures occur more frequently during intense rainfall, resulting in numerous deaths. Therefore, people's expectations for forest functions to mitigate disasters are high. Because of timber resource shortages worldwide, the forest industry has remained active, even in Japan. Therefore, in Japan, establishment of forest management methods to balance disaster mitigation function with timber production function has been sought. This paper introduces forest management methods along with a review of earlier studies.

\section{METHODOLOGY}

By reviewing previous studies in Japan, it is shown that the slope failure prevention function and flood mitigation function of forests are derived from forest soils, and that the tree root system contributes greatly to the maintenance of forest soils. Based on the results of the review, we will discuss forest management that balances the functions of slope failure prevention, flood mitigation, and logging timber production.

\section{RESULTS FROM THE REVIEW}

\subsection{Importance of forest soil in slope failure prevention and flood mitigation}

Until the 1950s, woods used for building and fallen leaves used for fuel or fertilizer were supplied from forests. Wood and fallen leaves tended to be harvested more than the forest could supply. As a result, forests have become oligotrophic, declining and bare. Bare land was distributed throughout Japan at that time. In the $1950 \mathrm{~s}$, area of about $27,400 \mathrm{~km}^{2}$ bare lands existed throughout Japan, whereas the forest area was about 250,800 $\mathrm{km}^{2}$ (Chiba [1]). However now, bare land has been nearly eliminated. This transformation is attributable to enforcement of greenery work, as shown in Fig. 1 and to the fact that fallen leaves are not collected anymore because of the wider use of fossil fuels and chemical fertilizer. 



Figure 1: Bare land in Japan before (left) and after (right) greenery work. In the greening work, saplings are planted along the contour lines of the terrace where the slopes have been cut out [9].

In addition to the fact that the bare land has almost disappeared, forests of Japan have matured since the 1960s, as represented by the fact that accumulation of trees has increased dramatically (Fig. 2). Before the 1950s, clear-cutting and reforestation have been done actively. However, after the 1960s, cutting down of trees has decreased due to stagnation of forest industry. New reforestation and young forest area also decreased, whereas areas of protected forests increased where logging was prohibited to control disasters.

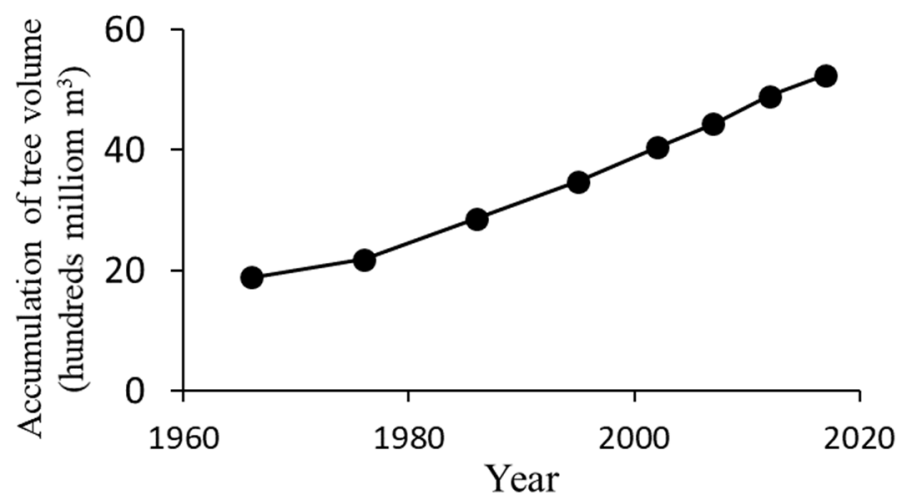

Figure 2: Transition of tree accumulation in Japan.

Keeping pace with the maturity of forests after the 1960s, the number of slope failure occurrences, areas damaged by flood water, and the number of deaths by heavy rain disaster decreased (Fig. 3). Suzuki [2] reported that slope failure occurring simultaneous frequently at almost all heads of streams during heavy rains were often observed before the 1980s. However, this sort of disaster is not observed since July 1983. Tamai [3] reports that the maturation of forests since the 1960s has improved the flood mitigation function of forests. This is because the development of tree roots suppressed the occurrence of slope failures and the forest soil developed. 


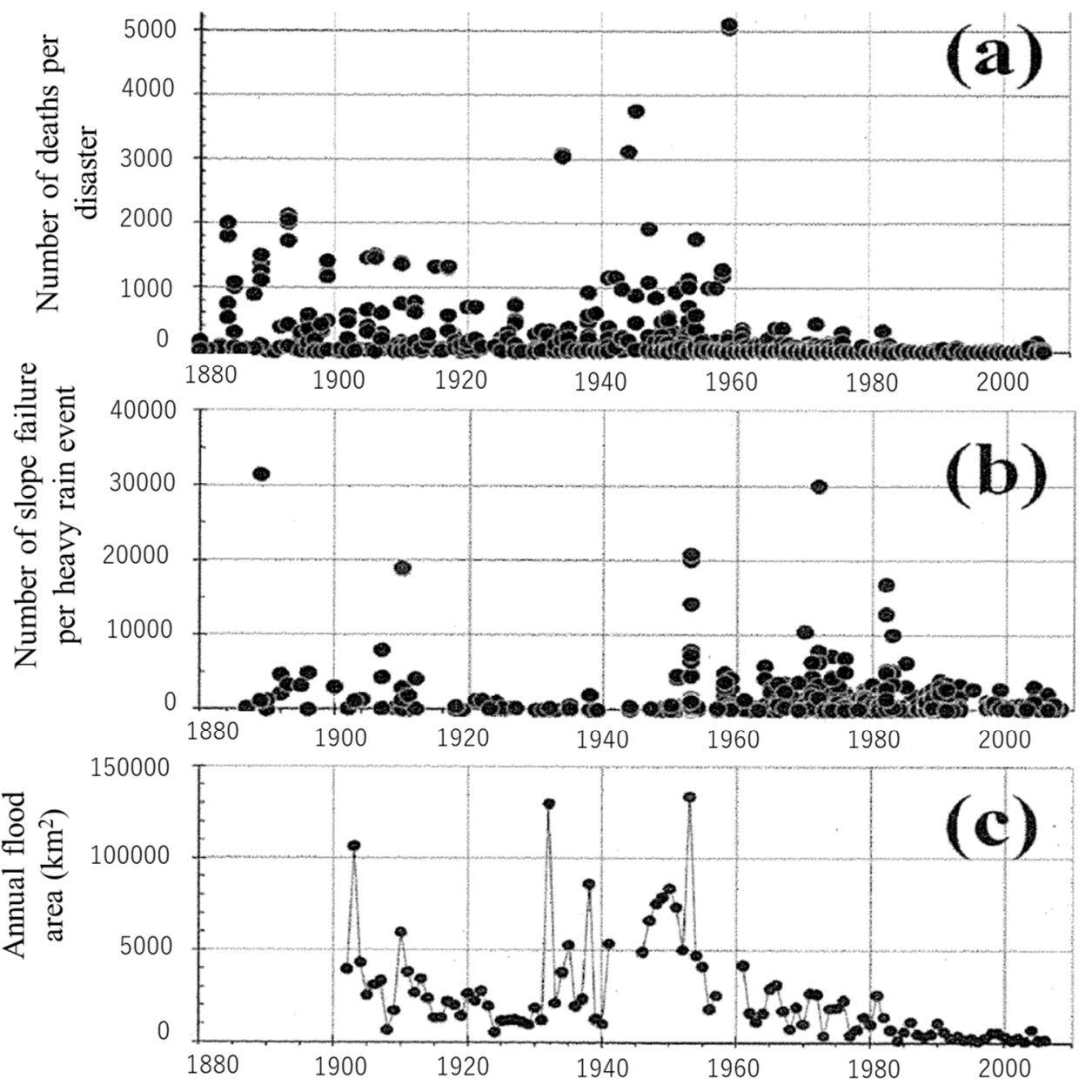

Figure 3: Year-to-year fluctuations in disaster damage in Japan. (a) Deaths people number; (b) Slope failure number; and (c) Flood area. (Source: Tada, 2018.)

As mentioned earlier, forest maturity is thought to have improved its function to mitigate slope failures and flood disasters. Related mechanisms are explained in the next section.

\subsection{Reinforcing effect of slope stability by root system}

Roots of forest trees elongate as they entangle themselves among the soil particles. The roots of the tree then strengthen the connections between the soil particles and prevent slope failure during heavy rains. This effect is called "reinforcing effect of slope stability by root system". For this effect, if forests are clear-cut, then the strengthen effects of soil connections by roots decrease as the roots of a stump decay. The reinforcing effect by tree roots replanted immediately after clear-cutting increases as it grows. Kitamura and Namba [4] evaluated changes of effects by decaying stumps and effects by growing roots of replanted trees over the years since clear-cutting and reforestation (Fig. 4). The results clarified that it takes about 
30 years before reinforcing effects by replanted tree roots become equal to reinforcing effects by tree roots before clear-cutting. It is also clearly recognized that reinforcing effects become minimal about 10-20 years after clear-cutting and reforestation. Tada [5] reported when slope failures occur as how many years after clear-cutting for two cases: reforestation is done after clear-cutting and the forest is left to natural recovery (Fig. 5). For natural recovery, the slope failure area continued to increase, whereas the number of years from clear-cutting increases. When reforestation is done after clear-cutting, the slope failure area reached a peak in the 20th year after clear-cutting.

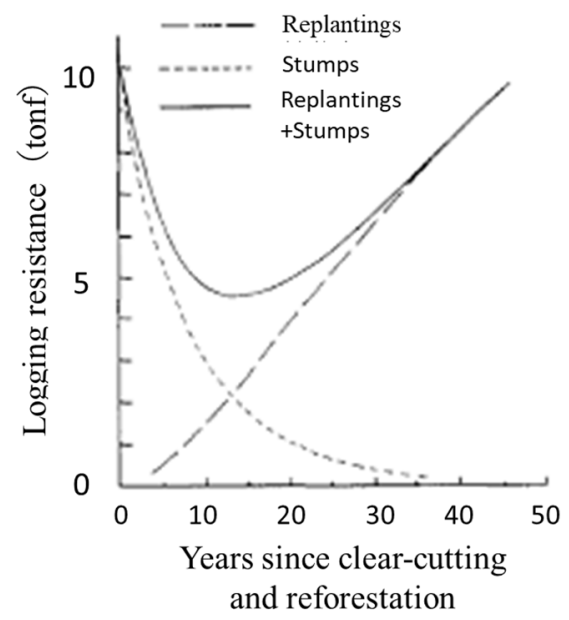

Figure 4: Changes in reinforcing effect of slope stability by root system over the years since clear-cutting and reforestation [4].

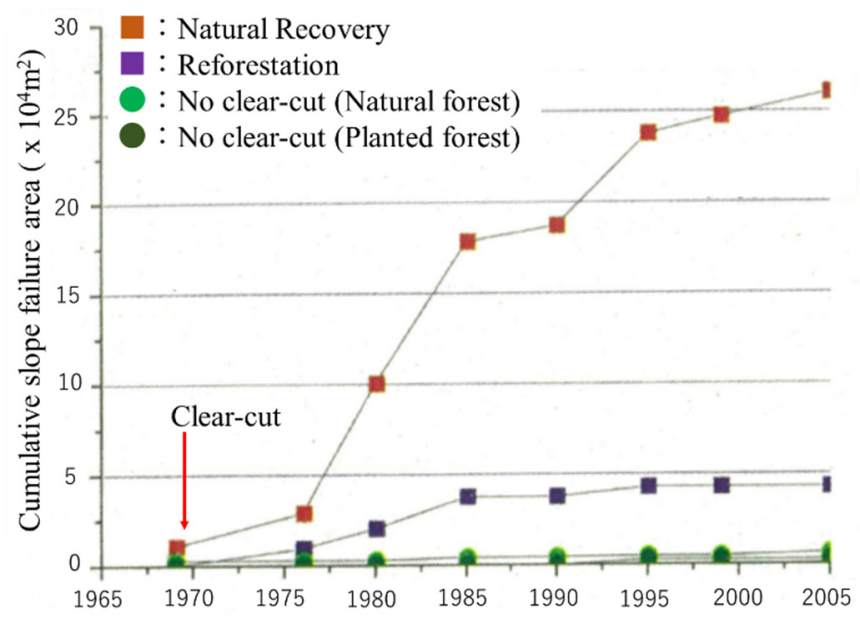

Figure 5: Difference in collapse area depending on the presence or absence of reforestation after clear-cutting [5]. 
For two adjoining forest basins where clear-cutting is made, Tamai [6] reported changes of the flood mitigation function of the forest as follows. Reforestation was made immediately after clear cutting in one basin. Results showed no reduction of flood mitigation function. In another basin, reforestation was not made immediately after clear-cutting. Subsequently, avalanche and slope failure occurred: about $20 \%$ of the basin area turned to bare area. The runoff delay effect of forest soil does not work on bare land (Tani et al. [7]). Therefore, it was observed that the flood water increased by $10 \%$. This indicates that the reinforcing effect of slope stability by root system also contributes to the flood mitigation function of forest.

\section{DISCUSSION TO ESTABLISH FOREST MANAGEMENT INCORPORATING DISASTER PREVENTION FUNCTIONS}

In the preceding section, forest functions to mitigate slope failure and flood disaster by heavy rains are explained to be contributed by the reinforcing effect of slope stability by root system. In this section, forest management considering the effects of root system is explained based on reports by Tada [5], [8].

\subsection{Concept of choosing a logging area from forests with disaster occurrence risk}

Tada [8] defined three conditions for places where slope failure occurs easily: (1) steep slopes (more than 25 degree slope), (2) weathering of ground is advanced (soil layer is clay), and (3) ground water is concentrated. Geography designated as the head of a stream, fault topography, landslide morphology, geological boundary, and alluvial cones are cited.

In such places, the soil mass of the slope moves gradually downward over many years. A characteristic microrelief is formed in these areas (Fig. 6). On the upper end of the soil mass, a depression occurs first, which is enlarged gradually to a crack, and a cliff. At the lower end of the soil mass, an obduction, engulfment and embankment of moving of the soil mass are generated. While the soil mass moves downward gradually over time, trees grow on the soil mass. Japanese cedar and cypress, which are popular tree planting species in Japan, grow such that the trunk is kept vertical. However, for cedar and cypress grown on a soil mass that is moving gradually downward, because of soil mass deformation, an originally vertical stem will tilt. Cedar and cypress with a bent stem strive to return to vertical; for that reason, the stem is bent like a bow. For forests with many cedar and cypress with bent stem, the soil mass can be inferred as shifting. In other words, existence of cedar and cypress with a bent stem constitutes important information for inference that some risk of disaster occurrence exists.

For forests with disaster occurrence risk, slope failures should be prevented by reinforcing effect of slope stability by root system. Since the slope is stable due to the reinforcing effect of the root system, the flood mitigation function is also maintained. To do so, it is ideal to avoid cutting down of forests with disaster occurrence risk. However, cutting down of trees might be unavoidable for production of timber, even in forests with disaster occurrence risk. In such a case, two strategies can reduce the risk of disasters by choosing where forests can be cut and where they should be preserved. One can rank areas by the degree of disasteroccurrence risk. Places judged to have disaster occurrence risk are divisible into high risk places and low risk places. Forests with lower risk should be selected for cutting. Also, one can rank areas by the occurrence of disaster bringing human damage or economic damage. When a slope failure occurs at a place where there is residential areas and agricultural regions that is immediately threatened, human damage or economic damage can be caused. However, at a place distant from residential areas and agricultural regions, even if slope failure occurs, human damage and economic damage do not occur. 


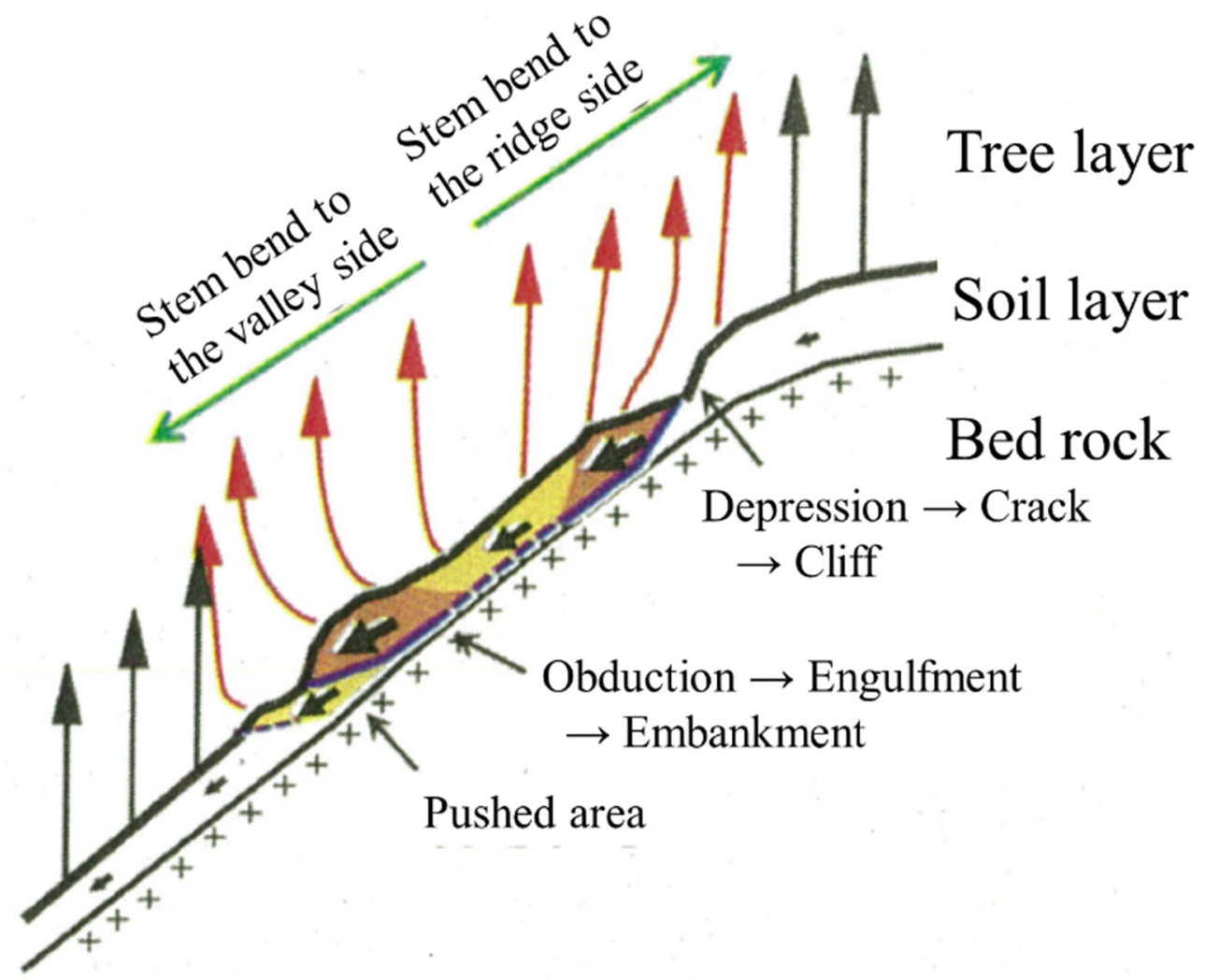

Figure 6: Typical examples of the microtopography of forests with a high risk of slope failure and the bending of standing trees [8].

\subsection{Forest measures to suppress disaster occurrence risk}

When a forest should be cut down at the place judged to present disaster prevention risk, forest selection is explained in the preceding section. In this case, measures should be taken so that an increase in the disaster occurrence risk is suppressed to the greatest degree possible.

First, suppression of the amount to be cut down is considered. The tree roots are effective for suppressing slope failure. Fewer trees being cut down leads to less tree root reduction. Therefore, not all trees should be cut down. More trees left uncut leads to a greater suppression of the increase of disaster-occurrence risk. In other words, the rate of cutting should be kept as low as possible for the area presenting high disaster-occurrence risk, thereby maintaining high tree density.

Also, replanting should be conducted promptly after cutting. Fig. 3 shows that it takes 30 years before the tree root of a newly replanted young tree to grow and reinforcing effect of slope stability to be effective. Fig. 4 shows that slope failure can start after five years from cutting down because of the decay of stumps. For this reason, it is crucially important to perform replanting immediately after cutting. This replanting reduces the amount of time that the reinforcing effect of slope stability is weak. 


\section{CONCLUSION}

The review showed that the forest slope failure prevention function and flood mitigation function are derived from forest soil, and that the tree root system contributes significantly to the conservation of forest soil.

Therefore, it is considered desirable for disaster mitigation to conserve the trees and maintain the root system. However, the timber production function is also one of the important functions of the forest.

When a forest should be cut down at the place judged to present disaster prevention risk, forests with lower risk or farther from the residential area is concluded to be selected for logging. In addition, it has also been concluded that limiting the number of loggings and prompt replanting after logging are essential.

\section{REFERENCES}

[1] Chiba, T., Bare land study in hilly mountains. Sosiete, p. 349, 1991. (In Japanese.)

[2] Suzuki, M., Influences of forest maturation on transition of sediment disasters. SABO, 100, pp. 2-7, 2009. (In Japanese.)

[3] Tamai, K., The evaluation of forest functions of flood control and water resources conservation. International Journal of Environmental Impact, 3, pp. 304-313, 2020.

[4] Kitamura, Y. \& Namba, S., Tree roots upon landslide prevention presumed through the uprooting test. Bulletin of the Forestry and Forest Products Research Institute, 313, pp. 175-208, 1981. (In Japanese.)

[5] Tada, Y., Aiming for both functions of forestry and national land conservation (2): Basic knowledge of disaster risk in forest area. Sanrin, 1641, pp. 34-43, 2021. (In Japanese.)

[6] Tamai, K., Effects of timber cutting on maximum and minimum daily runoff during non-snow season: Cases in Kamabuchi and Tatsunokuchiyama experimental watersheds. Journal of Japan Society of Hydrology and Water Resources, 34, in press. (In Japanese.)

[7] Tani, M. et al., Predicting the dependencies of rainfall-runoff responses on human forest disturbances with soil loss based on the runoff mechanisms in granite and sedimentary rock mountains. Hydrological Processes, 26, pp. 809-826, 2012.

[8] Tada, Y., Aiming for both functions of forestry and national land conservation (1): Concept of forest disaster risk for forestry engineers. Sanrin, 1640, pp. 37-45, 2021. (In Japanese.)

[9] Japan Forestry Agency. Greenery work in 1870-1910s, 2021. https://www.rinya.maff.go.jp/j/kouhou/archives/tisan/tisan.html. 